\title{
BIM 技术在装配式建筑设计中的应用
}

\author{
解广锋 \\ 天津市城市规划设计研究院 \\ DOI:10.32629/btr.v3i6.3174
}

\begin{abstract}
[摘 要] 本文将装配式建筑作为实例, 实际分析并且探讨有关于BIM技术在实现装配式建筑的深化设 计上具有哪些可实践性的方法与手段。就现有的BIM技术条件如何能够更加高效的完善装配式建筑的 主要设计要求,并且根据BIM技术在装配式建筑应用中的研究线索, 给总设计师和研究人员的角度提供 一些合理的见解, 让随后的BIM技术实践应用得以深入发展。
\end{abstract}

[关键词] BIM技术; 装配式建筑; 设计; 实践应用

BIM技术一一building information model, 即建筑信息模型技术。是一种将 建筑部件虚拟化、信息化, 并在其所建立 的平台上能够自由搭建零件形成信息化 建筑工程模型, 主要的便利途径在于各 个部门之间的设计都可以通过平台实现, 其采用的数据构建实现了设计时的信息 传递与共享化并且依据此进行更为完整 地技术革新, 通过其关联性和完整度, 让 建筑工程主体在设计初期到运营阶段以 及随后的维护过程中都能够根据采集的 信息达到全生命周期可参照化, 不同的 设计部门都采用数据进行构建建筑物主 体思路, 实现实时设计消息的传递与共 享新模式。其技术具有完整性, 关联性和 一致性等特点。我国近些年来在建筑领 域的突飞猛进让BIM技术的实践应用得 以更加广泛的应用与发展。

\section{BIM 技术的主体概述}

BIM技术的应用使建筑工程领域具 备了先进行与实用性进步, 其高效的协 调能力让建筑施工企业从工程师到承包 商到业主都采取了广为认可的态度。目 前这几年以来, 我国在装配式建筑的领 域高速发展, 新形势之下的建筑方式让 专业之间的协作模式出现了更加有效的 衔接, 管理度也相应的随之提升, 而应用 BIM技术作为装配式建筑整体的工作平 台有效的提升了工作效率, 并且减少了 很大程度部门与部门之间的设计错误。 设计中存在的不合理之处经过BIM技术
工作平台的处理可以得到相应的解决, 这也为实际建设上的细节问题提供了很 大的参考意见, 而且经过设计上的修改 可以成功避免多次返工, 这也为建筑企 业在建筑材料上节约了很多成本, 这部 分利润则可以更加充分的提升工作人员 的技术质量需要以及对建筑物的可靠程 度, 从推动建筑行业整体角度上而言, 切 实的做到了可持续化发展的必要条件。

装配式建筑在 20 世纪初就开始进入 建筑行业之中并且引起了整个行业的瞩 目, 但是由于技术的限制直至六十年代 才终于在英、法、俄等国家完成了首次 尝试。整体施工运用装配式进行建造让 工程进度变快, 并且其工程的造价成本 等却比正常建造要低, 这让整个建筑行 业看到了未来建筑业走向。

经过不断的改进与尝试, 装配式建 筑从最早期的呆板单一变成了现在的灵 活多变, 技术上的革新不仅让建筑能够 进行成批制造, 同时样式也丰富起来。美 国之前的一款活动住宅就是比较先进的 装配式建筑。其建造过程只需要将住宅 单元模型运送到制定位置, 再借由起重 机等进行安装。活动住宅的出现除了能 够作为单独的单元之外还能够与其他同 款或者同类型建筑进行连接, 从而增添 了装配式建筑的可行性。时至今日, 运用 当下的BIM技术能够更加精确的完成装 配式建筑设计目的, 在发挥了装配式建 筑多变性的同时也为建筑中的每一个细
节处进行精确核算。

2 具体实例解析 BIM 技术应用 于装配式建筑中的实践应用

通过P-BIM技术工作台的模型进行 引用, 以河北省的某企业的装配式建筑 作为范例, 从实际应用程度出发, 分析并 且探讨有关于BIM技术在实现装配式建 筑上从设计到竣工到后期维护都有着怎 样的应用性, 并以现有的BIM技术条件高 效性进行对未来BIM技术发展程度上提 供一些建议。

在具体示例的建筑模型中, 根据设 计要求需要将建筑面积设计在 372 平方 米。结构形式上操作的是自主压法的整 体装配式混凝土异型构件结构体系。装 载完毕Revit相关插件以及Tekla等两款 BIM应用程序进行整体建模, 其基础结构 建模的构件深化拆分以及加工施工图可 以在工作台中得到。

另外, 由于BIM的结构设计和技术路 线是将Revit建筑模型通过接口导入的 模式结构进行软件计算, 所得分析结果 在从结构分析模型导出至Revit, 最终形 成了Revit结构模型设计图。所得的 Revit可以通过各种剖切进行视图的细 节化展示并且能够在任意节点进行标注, 形成了主体施工结构与细节标注的双关 性文档设计图。实操中可以得到BIM结构 模型和结构分析模型间数据转换造成部 分信息错误以及丢失, 所以从无缝链接 的角度来看目前还不具备完善性的操控, 
这时就需要进行人工干预调整。也正因 为此, BIM技术结构设计应用还有一定的 障碍需要被攻克。

\section{3 基于 BIM 的构件深化设计实 践探索}

回到例子中, 具体工程之下的三层 别墅所需要的构件数量是大量的, 其中 异形梁需求量在 45 个, 异形柱需求量在 40 个, 证件内墙板需求量在 29 个。操作上 来讲需要将数据输入进平台, 但是因为 目前数据平台的参数节点不能深化分析 个体构件，所以通过构件拆分原则实现 Revit平台构件再创作, 这样个体构件得 到的数据将得到一致化, 并且构件与构 件间的从拆分到深化有了具体平台应用 模型

构件拆分模型的信息再次进入 Revit, 形成Revit结构模型包含构件界 面轮廓, 使用的技术信息材料都经过了 编辑达到能够使用的模型化。进入到布 局之内进行对各个模型的搭建与拆分。 Revit结构模型中的构件可拆分为更加 细碎的零件, 多个零件经过组合形成所 需要的的构件, 或者构件可以根据拆分 原则进行分解得到想要得到的零件。就 以别墅梁举例, 梁是叠合形式, 需要其正 在中位进行断开, 借由此进行构建拆分。
按照这方面的思路实行, 柱子, 楼板, 墙 面等均可以进行相关的构件拆分。

根据上述的构件拆分原则, 先进性 构件钢筋的参数信息。之后需要将钢筋 的使用模式先输入到平台的构件之上。 并以别墅的预制梁为例, 根据实际中预 制梁钢筋的使用情况与使用目的将信息 整合在Revit工作平台上, 随后将纵筋在 梁跨中后浇段中断开得到新的平台模型 数据, 根据后浇段的甩出长设计安装套 筒的具体长。在别墅的设计之中, 䈐筋密 度范围需要经过梁端的最大值进行设计, 生育梁端的根据构件拆分原则进行非加 密区的就位。纵筋断开的数据根究䈨筋 间距和数量等平台数据进行调用。平台 中的构件并非全部都有数据, 一些原件 数据也需要经过参数确认人为进行定 义。比如梁柱埋件, 需要通过埋件内嵌组 进行实现, 但是梁板之类的钢筋吊环则 是需要进行构建创作实现数据模型化, 并且设计完毕的构件需要经过平台添加 进工作台, 之后还需变动全局参数提高 各项数据模型的关联度, 这样就行实现 别墅预制柱墙柱连接处的钢板安装参数 了。墙板中埋件可以应用Tekla进行组件 自定义完成具体参数设置, 从而实现整 体建筑结构图的展示了。

\section{4 结束语}

本文以实际项目中的一小块位置进 行系统化示范, 通过对数据模型创建的 流程进行讲解外, 结合了当下BIM技术在 装配式建筑中的应用,集中展示了其优 势意义还欠缺的一些不足, 并为未来BIM 技术在装配式建筑的应用提供一些思 路。从工程个例中可以看出, BIM技术与 装配式建筑在整体工程应该用上是有着 相辅相成的功能的, 并且能够相应准确 的表达出设计意图, 这也从另一个角度 说明了从深化设计质量上, 减少设计容 错上, 缩短施工工期上, 后续建筑保养维 护上, 构件的配套生产上都具有了很好 的应用意义及基础。BIM技术的应用实现 了装配式建筑的产业化优势, 这也在为 我国当下建筑行业的大力发展上提供了 莫大的动力。

\section{[参考文献]}

[1]王淑嫱,周启慧,田东方.工程 总承包背景下BIM技术在装配式建 筑工程中的应用研究 [J]. 工程管理学 报,2017,31(6):39-44.

[2] 李丹梅.BIM技术在装配式建筑设 计中的应用[J].砖瓦,2020,(5):160-161.

[3]赵一萌.BIM技术在装配式建筑设 计中的实践[J].住宅与房地产,2020,(9):73. 